\title{
Ranking Projects in Multi-Criteria Environment
}

\author{
Zoltan Sebestyen \\ Budapest University \\ of Technology and Economics, \\ Budapest, Hungary \\ Sebestyen@mvt.bme.hu
}

\author{
Tamas Toth \\ Budapest University \\ of Technology and Economics, \\ Budapest, Hungary
}

DOI 10.5592/otmcj.2015.2.4

Research paper

\section{Keywords}

Portfolio management;

Project prioritization;

Project selection; Project ranking criteria; Monitoring

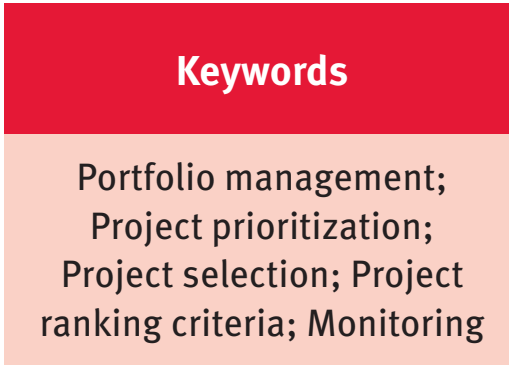

IN THE CONSTRUCTION INDUSTRY, THE WAY THE COMPANY MANAGES ITS PROJECTS IS A FUNDAMENTAL ISSUE. IT tools supporting project portfolio management have become widely available and widely used, however, some of their processes still significantly need to be refined and made more accurate. Choosing the right project is a vital element of their way to success or failure. This also means that when a building project becomes value-destroying, it has to be suspended, or even stopped. Making such decisions is vitally important for the company. The paper presents an integrated project prioritization model, which includes both financial and non-financial criteria. The conceptual idea is to integrate the financial element with the most widely used non-financial points of view that are already applied, tested and published in the relevant literature separately. The authors go over the steps of PPM one by one and in addition to the ranking of the outlined projects, also briefly summarize the basics of monitoring. 


\section{INTRODUCTION}

In order to achieve their strategic goals, companies more and more often choose project-oriented solutions from the many available tools. Due to globalization in business, the cross-border management of projects, more and more projects have to be managed at the same time and it becomes a more and more complex task. Issues in connection with this tendency have led to the formal appearance of project portfolio management, or PPM, and its whole set of tools have been developed. (Rajegopal el al., 2007).

Due to the complexity and size of the task, it requires considerable IT background. While the planning of a single project can sometimes be performed on a smaller network, and sometimes even traditional techniques can be used, carrying out the daily tasks of PPM is unimaginable without large systems connected into a network. The greatest software companies have clearly developed their project management solutions in the direction of portfolio management (Hewlett Packard - Project and Portfolio Management Center, Microsoft - Project Portfolio Server, IBM - Rational Portfolio Manager, Computer Associates - Project and Portfolio Management, Compuware - Changepoint). It is no accident that capital-intensive industries, such as enterprises connected with public utilities or communal facilities have clearly turned their attention to PPM (Chapel, 2007).

The project approach can cause delays and resource problems without proper management, that is, portfolio management (Blichfeldt-Eskerod, 2008). A study made in 2004 points out that a high level of acceptance of PPM in the organization clearly leads to a decrease in project-related problems and an increase of performance (De Reyck et al., 2005). It is obvious that the attention of professions connected with project management has turned to PPM.
The ubiquitous project portfolio approach has a significant impact on modern organizations. Handling the fast growing number of projects has become one of the most important tools for achieving organizations' strategic goals, and as Olsson (2008) and Teller and Kock (2012) argue, in a project portfolio environment the practice of single project management (SPM) has been increasingly loosing sufficiency, while project portfolio management (PPM) is recognized as one of the most crucial challenges of organizations. In our article, we use the definition based on the approaches of Archer and Ghasemzadeh (1999) and Martinsuo and Lehtonen (2007) to project portfolio. In this term the portfolio is a group of rival projects striving for sparse resources carried out under a single sponsorship and management of an organization in line with the strategy. Recently, the portfolio-wide perspective of project portfolio management goes well behind single project management that focuses only the processes of one project, and ignores synergistic effects with the others.

Project portfolio management is about managing multiple projects, programs, sub-portfolios, and operations as a group to achieve strategic objectives (Project Management Institute, 2013). The first step of PPM is project portfolio selection (adding, taking out, and prioritizing projects) including periodic activities that involved in the selection from available projects meeting the organization's objectives according to constraints (see e.g. Archer and Ghasemzadeh, 1999). Thus, as Nowak (2013) argues, project portfolio management is a recurring dynamic and interactive decision process, where the portfolio must be constantly updated and revised. The result of this process is a constantly available well-selected and ranked set of projects.

In the literature there are two distinct directions of research on selecting project portfolios (Nowak, 2013). In the first group there are articles providing general recommendations with few systematic procedures especially addressed to practitioners. The second group includes quantitative decision support techniques dedicated to researchers mainly. However, it is beyond debate on both sides that for selecting the right projects at the right time multiple criteria should be taken into account and recently a significant number of literature has become available on methodological tools for this (Gutjahr et al., 2010; Anagnostopoulos and Mamanis, 2010; Kremmel et al., 2011; Elazouni and Abido, 2011). These sources provide complex, formal mathematical solutions for multi-objective cases in project portfolio selection, but besides the thorough operational issues, the criteria selection is left out of scope. These techniques employ sophisticated computation tools, but the models suggested often oversimplify the problem.

The portfolio must be filled with projects, then after continuous evaluation and ordering, the status of the projects need to be constantly revised according to the evaluation. The status of a project can be active, suspended, withdrawn (terminated) or requiring special priority. Since the portfolio needs to be tested constantly so that the status of the projects conforms to the system of criteria, this is a cyclical process. While a project is a finite, single and individual undertaking, PPM is a continuous operative activity of a company.

The following formal steps must be followed in PPM (Rad-Levin, 2006; Levine, 2005):

1. Filling, ranking, selecting and continuous maintenance of the portfolio according to a logical and formalized system of criteria. - Ordering has to be done clearly and in a centralized manner. The current projects have to be compiled into a database 
according to their status. During the first step it turns out which projects stay in the portfolio for a long time.

2. Assigning the human, material, information and technological resources in the resource center, and the attention of the management based on the ranking. - The second step shows where parallel special priority projects causing resource peaks are, and therefore the allocation of resources can be carried out at the portfolio level.

3. A methodological execution and follow-up of active projects in the portfolio. - In the third step the cyclical revision and evaluation of projects need to be done (therefore there is feedback to point 1).

4. The emerging important question is what quantitative and qualitative criteria must be considered and how to include them in a portfolio selection system that will be suitable for both practitioners and researchers.

\section{Ranking Criteria for Project Portfolios}

Ranking by net present value (NPV) is a common practice that results in dropping the financially weakest projects from the portfolio. However, the standard method for NPV calculation often only focuses on easily calculable events and processes, thus the more subtle details and benefits of the project may be missed out of the assessment.

Our view is that project ranking should look beyond NPV by setting up a more sophisticated criteria system. To establish a sound system, the development of a well-structured hierarchy seems necessary.

\section{Financial Criteria (FI)}

In the mainstream "perfect market" framework of finance, the only criterion is Net Present Value (NPV), which shows the added value of a business idea. If there are infinite resources, and no market frictions, all projects with positive NPV are undertaken. If the resources are scarce, e.g. there is a limited budget, project ranking is needed. The simplest project ranking method is the ranking by the NPV/CAPEX ratio, referred to as Profitability Index (PI), indicating the project financial value expected to be generated by one unit of the investment.

A project's Profitability Index can be given as the ratio of NPV and actual capital expenditures (CEXP,i). Ranking by PI is obvious: the higher the PI is, the higher the project must be prioritized.

\section{Strategic Criteria (STI)}

Business strategies often declare quantifiable but hardly monetizable objectives (e.g., increase of market share, improvement of business performance). Literature review suggests that the project portfolio management serves as an important and effective tool for strategy implementation. Moreover, all the project portfolio management process must be subordinated to the strategy of the organization (Archer and Ghasemzadeh, 1999; Martinsuo and Lehtonen, 2007; Voss and Kock, 2012; Teller and Kock, 2013). Meskendahl (2010) examined the interference of the strategy, project portfolio management, and the success to draw together strategy formulation and implementation. Although existing research shows a positive relationship between isolated concepts, he claimed a lack of a coherent and integral framework from strategy to success. Therefore, Meskendahl conceptually extended the current research in portfolio management by strategic orientation. Killen et al. (2012) conducted research on the application of strategic management theories to project management and project portfolio management. These research experiences outline the successful application of strategic management theories highlighting the advantages as well as the challenges of adopting theories from strategic management for PM and PPM research. Their paper makes primary contributions to the PM, PPM, and strategic management fields, and as a conclusion, it provides an obvious evidence of benefits that can be obtained by the application of strategic management approaches to PM and PPM research. PM and PPM are defined as subsets in management and strategic management research rather than as separate domains. As it is an adequate statement for project management, project portfolio management must also be aligned to strategy, therefore a strategic element is taken into consideration for evaluating, prioritizing, and selecting projects properly. Since there is a positive correlation between the strategy-conform portfolio selection and project portfolio performance (Müller et al., 2008), we suggest strategy criteria to be included in the project ranking exercise. Projects with higher alignment with the strategy should be ranked higher than those more independent of the strategy.

\section{Stakeholders Criteria (SHI)}

Business projects owned by enterprises normally have many stakeholders. Success or failure largely depends on the project's conformity with the expectations of the society and local communities, as well as with the prevailing political regimes and legislation. Other key success factors may include the cooperativeness of business partners and the quality of the available services and suppliers.

In recent literature review the significance of stakeholders appeared. Unger, Gemünden and Aubry, (2012) outlined the importance of stakeholders in project portfolio management. Project portfolio management offices (PPMOs) are centralized units and subsets of project management offices (PMOs) responsible for the organization's portfolio focusing on the 
demands of various stakeholders. "[T] he tasks of PPMOs may be derived from these key stakeholders' requirements and their need to delegate management obligations" (Unger, Gemünden and Aubry, 2012, p608). Also, PPMOs have to guarantee the implementation of stakeholder interests and needs besides the organizational goals. Their comprehensive role-based research outlining organizational issues basically stemmed from the stakeholders' demand. Beringer, Jonas and Kock (2013) refer to the stakeholder behavior and stakeholder management as key success factors within portfolio management. Their empirical study project portfolios investigating the effect of portfolio-internal stakeholders on project portfolio success pointed out a clear impact of stakeholders. Even the latest version of PMBoK (2013) extended the set of knowledge areas with the project stakeholder management. Although the literature expresses the significance of the stakeholders in their methodologies only implicitly, the underlying models do not take sufficient note of that. Agreeing with the literature above emphasizing the importance of stakeholders, we also state that it must be a determinative and fundamental element in portfolio selection. We go further than the referred sources, and think that the criterion of stakeholder is worth pulling out of the large conceptual criteria set and treating independently in the ranking model.

Creating a lobby map accommodating all the stakeholders affecting the project is especially crucial for large-scale and complex projects. Negligence or undervaluation of stakeholders' interests may result in serious difficulties in the projects' implementation phase, or as a worst case, may lead to the premature end of the project. Projects with wider acceptance from stakeholders should be ranked higher than those with non-compliance or resistance to them.
Learning Criteria (OLI)

Long-term business success may depend on whether the organization is capable to learn from its own previous projects and is able to turn the lessons learned into future potential benefits. For instance, Gutjahr et al. (2008, 2010) built models for project portfolio selection, paying specific attention to competence development. Their model is based on the gains from the increment of desirable competences. The tools proposed are rather sophisticated (nonlinear mixed-integer program, greedy heuristics, metaheuristics, etc.), however, they seek an optimal staff assignment, and criteria from other fields are left out. Killen et al. (2012) conducted a research project on PPM and also outlined the significance of knowledge and learning. Although strategic management theories are applied recognizing the significance of learning for project and portfolio management, the criteria set is limited (e.g. lack of financial thinking). In the work of Purnus and Bodea (2014) criteria related to project opportunity including experience that leads to a competitive advantage for a successful portfolio project management emerged. They built a large and complex set of criteria. For a more practical model, some less significant criteria can be left out (i.e. contractual conditions), and some of them can be merged (financial criteria can handle the important risk-related questions). The opportunity for learning gained during a project is always a challenge to quantify, but it is obviously to be considered to ensure future benefits. Projects from which we learn more contain more exploitable potential and should be ranked higher than those without learning.

\section{Utilization of the Proposed Ranking Criteria}

With the above-mentioned method, therefore, a calculated value can be assigned to every project, with which the projects can be ordered easily.
In cases where the company has no significant limit on the resources (in a perfect market this is true in the long run), ranking projects with a positive PP (project priority) yields the list of projects to be carried out.

However, companies often have a limit on resources. In addition, these limits are sometimes realized in very different ways. One of the most common bottlenecks is the limit on financing, which can vary in consecutive years. The situation is complicated by the fact that a project can take several years to complete, influencing the list of projects that can be done at that time. A surprisingly common bottleneck is the number of reliable, experienced project managers who the individual projects can be given to. Predetermined tasks, such as supplementary investments of certain machines, or the investments of compulsory tasks (as dictated by law) also affect projects that can be carried out later. A bottleneck can simply be an existing manufacturing capacity, for which the various projects can compete.

In such cases mathematical programming (MP) can provide a solution. Although attempts to integrate mathematical programming into PPM have been made earlier (see Martin, 1955, Ghasemzadeh et. al., 1999.), optimization was made specifically for financial indicators. The new selection method suggested below also takes into account non-financial aspects, which significantly affect how a project conforms to company strategy. The target function in our case is to select along the bottlenecks the project portfolio providing the highest added PP value:

$$
\sum_{k=1}^{N} \mathrm{PP}_{\mathrm{k}} \mathrm{x}_{\mathrm{k}} \rightarrow \max
$$

where $\mathrm{k}$ is the number of projects and $x k$ is the result variable indicating the implementation of project $k$.

In a general case it is usually assumed that projects are indivisible, 
in other words, a project cannot be "half implemented". In this case xk can only be o or 1 , that is, the project is implemented or not. This MP problem type is called integer programming. In this case the first condition of mathematical programming:

$\mathrm{x}_{\mathrm{k}} \in\{0 ; 1\}$

There are projects, however, which are actually divisible and investment and related cash flows change proportionally. Then the above condition is less strict, the criterion is only that the value of $x k$ is between $o$ and 1 :

$x_{k} \in[0 ; 1]$

Naturally, $x k$ is usually not continuous, so in the latter case other conditions have to be provided for the possible discreet values of $x k$. It is worth noting that a change in an individual condition can drastically alter the algorithms that can be used for the solving of MP problems.

If projects are divisible, but its related cash flows do not change proportionally, it is better to divide the project into project parts and to provide a condition saying these project parts are connected, e.g. if projects 2, 3 and 4 are connected: $x 2=x 3=x 4$. Programs can be handled with the same method.

Then any restricting conditions can be given, such as capital constraints (KCAPEX) in the year of the investment and capacity restraint (e.g. usage of production line capacity) in the first year:

$$
\begin{aligned}
& \sum_{k=1}^{N} F_{0, k} x_{k} \leq K_{\text {CAPEX }} \\
& \sum_{k=1}^{N} a_{1, k} x_{k} \leq 1
\end{aligned}
$$

where Fo, $\mathrm{k}$ is the investment capital requirement of project $k$ and $a 1, k$ is the capacity used by project $k$ in the first year.

Any other restraint can be built into the MP problem. Naturally, it is true here too that such refined methods are only worth using if the reliability of input data justifies it. The solving of the above MP problems requires very high computing capacity in the case of a higher number of projects (above 40). This is because no optimization algorithm of integer programming is known (the problem is known as the backpack problem). In such cases all possible combinations have to be calculated, that is, the variant yielding the highest total PP value has to be chosen from $2 \mathrm{~N}$ possibilities, while the fulfilling of conditions also has to be checked for each combination.

Only in recent years has the computing capacity been available to solve such problems, and the method is therefore becoming more popular.

After analyzing financial elements, let us include non-financial elements in the criteria and define an index with these! The main steps of a general PPM process (portfolio setup, evaluation, prioritization, selection, execution etc.) were integrated with more phases by e.g. Teller et al. (2012). This research, however, mainly concentrates on the mathematical implementation and realization with bi-criteria or multi-criteria analyses. Ballestero and Romero (1996) provided a solution by defining a bi-criteria utility function for portfolio problems to average investors. Gutjahr et al. (2010) formulated a multi-objective optimization model including employee competences and their evolution, and Anagnostopoulos and Mamanis (2010) developed a three-objective portfolio optimization model with discrete variables considering further financial components. For the complex ranking problem we studied, however, the AHP (Saaty, 1977) provides a flexible, multiobjective method that involves even the hierarchy of criteria.

The focus of our investigation is to provide an integrated ranking model combining financial parameters with additional non-financial elements important for managing portfolios. The proposed ranking method is based on the four criteria groups discussed above resulting in the overall Criteria Indices: FI - Financial Index, STI Strategy Index, SHI - Stakeholder Index, OLI - Opportunity for Learning Index.

Based on the criteria above the overall Project Priority Index (PPI) is as follows:

$$
\begin{aligned}
& \mathrm{PPI}_{\mathrm{i}}=\mathrm{a} \times \mathrm{FI}_{\mathrm{i}}+\beta \times \mathrm{STI}_{\mathrm{i}}+\gamma \times \mathrm{SHI}_{\mathrm{i}}+ \\
& \delta \times \mathrm{OLI}_{\mathrm{i}} \\
& \mathrm{a}+\beta+\gamma+\delta=1
\end{aligned}
$$

where $a, \beta$, $\gamma$ and $\delta$ are the respective group weights also to be defined by the management preferences. Only those highest PPI projects can be enter into the project portfolio, whose summarized capital expenditures (CEXP,i) do not exceed the CAPEX budget defined by strategy.

\section{Monitoring and Control}

After evaluation and portfolio optimization, decision-makers classify the projects, which they keep active, so the list of projects in the active portfolio is determined. Then the business plans of the projects are carried out consistently and methodologically. There are advanced techniques to control the progress of the project (Hajdu et al. 2013). During execution the progress of projects in the portfolio has to be measured and evaluated. In the investment phase of projects it is the tools of project management that dominate, that is, focus is on the effective implementation of the plans.

In this phase the easiest way to monitor projects is the use of milestones. In the management of large, complex projects containing many activities and connections the use of milestones is still a necessary but not sufficient element of the monitoring system. In the monitoring of costs and progress, earned value management (EVM) has a more and more important role. In some countries such as the USA the law requires tracking by EVM in state projects. The essence of the 
analysis is that it compares planned and actual costs incurred up to the given point. In addition to time and cost parameters, it also takes into account which stage the activities are in a way detailed below. A continuous comparison of planned and actual values can be used to make predictions and to correct undesirable deviations (Project Management Institute, 2013).

In implementing projects accurate data is needed concerning the budgeted cost of work performed (BCWP), the actual cost of work performed (ACWP), and the budgeted cost of work scheduled (BCWS). One of the most decisive professional journals, PMBoK uses a simpler name for these parameters (Project Management Institute, 2013): earned value (EV), actual cost (AC) and planned value (PV), respectively. Further calculations and analyses are not detailed here but a minimum that has to be calculated is the cost performance index (CPI = BCWP) $A C W P$ ) and the schedule performance index (SPI = BCWP/BCWS). Cost variance (CV) and schedule variance (SV) have a similar role. The indicators show the relationship of the project to the budget and the project's progress relative to the plan, however complex the project is (Project Management Institute, 2005). EVM is excellent for the clear, comprehensive and uniform tracking of projects executed in the portfolio.

Although EVM is an undoubtedly useful technique, it has drawbacks. On problem is that the unit of measure is always money unit or working hour - it does not contain time (time is also expressed in money units). This way it is often difficult to interpret the results, especially if we wish to draw further conclusions from time. Another problem of the method is that towards the end of delayed projects EVM's timerelated indicators (SV and SPI) yield an over-optimistic result. At the end of the implementation phase of the project however much the delay was -SV will always be zero, and SPI will be one. The reason is that at the end of the project $P V$ is equal to the budget plan even if the project was finished with a considerable delay.

Based on the measurements of Lipke and Henderson (2007), these schedule indicators usually start to become optimistic when the project is about $65 \%$ finished. It can be stated that after this the SV and SP indicators are less useful for the management. These disadvantages can be eliminated with the use of ES, or Earned Schedule (Lipke 2003). ES is an indicator system to be used with EVM and uses SV(\$) and $\mathrm{SV}(\mathrm{t})$ instead of $\mathrm{SV}$, and SPI(\$) and SPI(t) instead of SPI, in order to increase accuracy. The dollar sign is often omitted. Naturally, ES has to be calculated. The basic idea of ES is simple. The time period in which earned value (EV) is as much as it should have been according to the plan.

Toward the end of the investment and implementation phase financial evaluation methods come to the forefront again, because a project ready to operate can also be sold, outsourced or even stopped. To make a decision, evaluation is necessary, for which the financial indicators of the project have to be calculated again. In the operation phase of the project probably the best method is to regularly make plan-fact comparisons for the cost and income data of the business plan. This can also eliminate a kind of serious commissioner-agent problem: managers are often interested in starting a project they planned or managed because this improves their reputation, and consequently their earnings. Especially in companies where managers only spend 2-3 years in a position, incomes are often overplanned and costs are often underplanned, that is, the business plan of the project is too "optimistic". Regular plan-fact comparisons and the related compensation system can greatly reduce the scope of this “over-optimism". Another advantage of plan-fact comparisons is that makes it easier to notice significant deviations of factual data from the plan, which clearly indicates that the business plan of the project has to be revised.

Summary and Conclusions

In the paper first the modern concepts of project management and project portfolio management were defined, then the general model of project portfolio management was presented, which also integrates the more sophisticated project selection method we suggest.

The recommended PPM framework enables companies to keep a project portfolio of many simultaneous projects in spite of limited resources, and effectively manage executed projects according to strategic goals. The theoretical basics of project portfolio management have been available for a long time but only now are information technology systems widely available and affordable to carry out project portfolio management cost effectively.

There are numerous portfolio management software packages on the market but these mainly support the management of projects. There are software packages supporting the selection of an optimal project portfolio but in some cases the algorithm used is known to be unreliable, while in some other cases the method of optimization is surprising (e.g. in the case of all project pairs a management preference has to be given, that is, which of the two would we choose, and ranking is made based on these preferences.) We are convinced, however, that PPM systems will develop very fast, especially concerning the methods of selection. 


\section{References}

Anagnostopoulos, K.P., Mamanis, G.A. (2010). A portfolio optimization model with three objectives and discrete variables. Computers \& Operations Research, 37, 1285-1297.

Archer, N.P., Ghasemzadeh, F. (2004). Project Portfolio Selection and Management. In: Morris, P.W.G., Pinto, J.K. (Eds.), The Wiley Guide to Managing Projects. John Wiley \& Sons Inc., New York, 237-255.

Archer, N.P. Ghasemzadeh, F. (1999). An integrated framework for project portfolio selection. International Journal of Project Management, 17(4), 207-216.

Ballestero, E., Romero, C. (1996). Portfolio Selection: A Compromise Programming Solution. Journal of the Operational Research Society, 47, 1377-1386.

Beringer, C., Jonas, D., Kock, A. (2013). Behavior of internal stakeholders in project portfolio management and its impact on success. International Journal of Project Management, 31(6), 830-846.

Blichfeldt, B. S., Eskerod,P. (2008). Project portfolio management - There's more to it than what management enacts. International Journal of Project Management, 26(4), 357-365.

Chapel, S. (2007). Utility Project Portfolios Can Be Managed with Modern Tools. Natural Gas \& Electricity, October, 12-16.

De Reyck, B., Grushka-Cockayne, Y., Lockett, M., Calderini, S. R., Moura, M., Sloper, A. (2005). The impact of project portfolio management on information technology projects. International Journal of Project Management, 23 (8), 524-537

Elazouni, A., Abido, M. (2011). Multiobjective evolutionary finance-based scheduling: Individual projects within a portfolio. Automation in Construction, 20, 755-766.

Gutjahr W, J., Katzensteiner, S., Reiter, P., Stummer, C., Denk, M. (2010). Multi-objective decision analysis for competence-oriented project portfolio selection. European Journal of Operational Research, 205, 670-679.

Gutjahr, W.J., Katzensteiner, S., Reiter, P., Stummer, C., Denk, M., (2008). Competencedriven project portfolio selection, scheduling and staff assignment. Central European Journal of Operations Research, 16(3), 286-306.
Hajdu, M., Szenik, G., Bardócz, G. (2013). Application of Evaluation Lines in Project Planning and Control. Procedia - Socilal and Behavioral Sciences, 74, 175-18o.

Killen, C.P. Jugdev, K, Drouin, N, Petit, Y. (2012). Advancing project and portfolio management research: Applying strategic management theories. International Journal of Project Management, 30(5), 525-538.

Kremmel, T., Kubalík, J., Biffl, S. (2011). Software project portfolio optimization with advanced multiobjective evolutionary algorithms. Applied Soft Computing, 11, 1416-1426.

Levine, H. A. (2005). Project Portfolio Management: A Practical Guide to Selecting Projects, Managing Portfolios, and Maximizing Benefits. Jossey Bass

Lipke, W. (2003). Schedule is Different. The Measurable News, Summer, 31-34.

Lipke, W, Henderson, K. (2007). Earned Schedule an emerging enhancement to EVM. www. earnedschedule.com, Retrieved 2007

Martin, A. D. (1955). Mathematical Programming of Portfolio Selections. Management Science, 1(2), 152-166.

Martinsuo M., Lehtonen, P. (2007). Role of singleproject management in achieving portfolio management efficiency. International Journal of Project Management, 25(1), 56-65.

Meskendahl S. (2010). The influence of business strategy on project portfolio management and its success - A conceptual framework. International Journal of Project Management, 28(8), 807-817.

Müller, R., Martinsuo, M., Blomquist, T. (2008). Project portfolio control and portfolio management performance in different contexts. Project Management Journal, 39(3), 28-42.

Nowak, M. (2013). Project Portfolio Selection Using Interactive Approach. Procedia Engineering, 57, 814-822.

Olsson, R. (2008). Risk management in a multi-project environment: an approach to manage portfolio risks. International Journal of Quality \& Reliability Management, 25(1), 60-71.

Project Management Institute (2013). A Guide to the Project Management Body of Knowledge (PMBOK Guide), 5th Ed. Project Management Institute, Newton Square, Pennsylvania, USA

Project Management Institute (2005). Practice Standard for Earned Value Management
Purnus, A., Bodea, C.N. (2013). Considerations on Project Quantitative Risk Analysis. Procedia - Social and Behavioral Sciences, $74,144-153$.

Rad, P. F., Levin G. (2006). Project Portfolio Management Tools and Techniques, IIL Publishing

Rajegopal, S., McGuin, P., Waller J. (2007). Project Portfolio Management: Leading the Corporate Vision. Palgrave Macmillan

Saaty, T. (1977). A scaling method for priorities in hierarchical structures. Journal of Mathematical Psychology, 15(3), 234-281.

Teller J., Kock, A. (2013). An empirical investigation on how portfolio risk management influences project portfolio success. International, Journal of Project Management, 31(6), 817-829.

Teller J., Unger, B. N., Kock, A, Gemünden, H. G. (2012). Formalization of project portfolio management: The moderating role of project portfolio complexity. International Journal of Project Management, 30, 596-607.

Unger, B. N., Gemünden, H. G., Aubry, M. (2012). The three roles of a project portfolio management office: Their impact on portfolio management execution and success. International Journal of Project Management, $30,608-620$.

Voss, M., Kock A. (2013). Impact of relationship value on project portfolio success Investigating the moderating effects of portfolio characteristics and external turbulence. International Journal of Project Management, 31(6), 847-861. 